\title{
The Impact of Training Methods on Effective Training Process in Ajman Police: The Moderating Role of Readiness for Training
}

\author{
Abdulla Awadh Abdulla Abudlhabib \\ Management Science University (MSU), Malaysia, Ministry of Interior, Ajman Police, U.A.E \\ E-mail: Abdulla.awadh.a@gmail.com
}

Hassan Al-Dhaafri

Assistant Professor, University of Dubai, Dubai Police, Dubai, United Arab Emirates

E-mail: hassan_saleh3@hotmail.com

Received: Nov. 6, 2019 Accepted: March 4, $2019 \quad$ Published: April 1, 2020

doi:10.5296/jmr.v12i2.16483 URL: https://doi.org/10.5296/jmr.v12i2.16483

\begin{abstract}
The present paper primarily aimed to examine the joint effect of training methods and readiness for training on the effective training process (ETP). The paper conducted an examination of the proposed study model, using the survey questionnaire design. Data were gathered from Ajman police departments by distributing 252 questionnaire copies. From the copies distributed, 172 questionnaires were retrieved, from which data was analyzed using SEM-PLS. On the basis of the statistical results obtained, training methods significantly affect ETP. The study provides several implications, both theoretical and practical, and the findings are expected to assist in the proper decision-making of managers when it comes to training methods effective implementation in organizations. This is one of the pioneering empirical studies that investigated the influence of training methods and readiness for training on ETP.
\end{abstract}

Keywords: Training methods, Effective Training Process (ETP), readiness for training. 


\section{Ajman Police History}

Founded Ajman Police in early 1967, under the name of the leadership of the police and public security, where His Highness the late Sheikh Rashid Bin Humaid Al Nuaimi, Ruler of Ajman then ordered the establishment of the police, and was appointed by HH Sheikh Abdullah Bin Rashid Al Nuaimi, Commander of His Highness Sheikh Saeed bin Rashid Al Nuaimi his assistant.

Since the establishment of the police started exercising the functions assigned to them in maintaining security within the emirate, and those exceeding the tasks was to guard and traffic regulation, and the number of individuals and officers, not to exceed twenty, then the number has increased gradually depending on the increase and the multiplicity of functions of the police.

The police and security apparatus in Ajman, did not lag behind the progress and development achieved by the police and security services with the beginning of the State of the Union, which merged together to the Ministry of the Interior, This is a new stage and a real beginning to build a modern police. Bakanonuahd where he began working for the police and security, and police were able to achieve significant progress and development, thanks to the attention and care on the part of His Highness the President and his brothers, Their Highnesses Rulers of the Emirates.

The development and progress that has occurred to the police in Ajman has emerged significantly in the security facilities of modern with the latest devices and equipment, as well as the increase in Adeddalillat and non-commissioned officers and individuals working in various departments and divisions, units and centers of Ajman Police, furthermore, provides the potential and Alojhzhalmttorh that help the police on the performance of their business to serve the citizens and residents of the state.

Did not skimp on the Ministry of Interior security forces and even provided her all the way forward and Alttorpma guaranteed to perform its security responsibilities to the fullest, and in this context, the Cherthagaman using the latest computer programs in many departments and areas such as traffic management, licensing, police stations and the Department of planning and development processes, it which is easy for employees to access the information required less time and effort. Ajman Police has prepared a future plan which will create several centers in different police areas in the Emirate of Ajman.

\section{Introduction}

Staff training is currently viewed as a company investment, as the staff tasks and responsibilities are geared towards meeting the needs of the company, while expecting reciprocal good returns from the company. In this background, policy work and its influence on the society is a complex subject, with the role of the police officer being ambiguous, requiring discretion for duties performance. Officers require minimum to no education during training on discretionary use and stress handling. This leads to the issue of high stress experience of officers during their duties, and such stress can be transferred to family members. Stress refers to a stage of extreme difficulty, pressure or strain, and it can disrupt 
the physical, mental or emotional health of the individual when responding to negative external influences (Merriam \& Webster, 1980).

Throughout the past decades, training and human development activity has shown considerable increase and in this regard, it has been estimated that more than $\$ 40$ billion is incurred on human resource development (HRD) and training in the context of universities and colleges in the U.S. (Fulmer, 1988, p.57). This HRD expense calls for evaluating the effectiveness of training and HRD program in its meeting of the expected objectives and aims.

\section{Related Literature Review}

\subsection{Introduction}

This study reviewed literature on the issues linked with the study variables including training methods and training readiness as well as effective training process. The research framework development and hypotheses are provided, based on the relationship among the variables, after which the study presents the theoretical framework.

\subsection{Training Process}

In the past several years, multiple models were used to provide a description and analysis of the training process construct that mainly viewed training as a cycle that consists of several stages, beginning with the identification of training requirements and culminating in the evaluation of training effectiveness. The models vary based on their number of stages and the stress on any one of them. In the next sub-sections, the study provides a detailed presentation of training definition, objectives and characteristics, learning level, behavioral level and results level.

\subsubsection{Definition of Training}

This study views training as the planned intervention designed to improve the determinants of the job performance of the employee (Chiaburu \& Tekleab, 2005, p. 29). The concept of training is linked to the skills required by the management to be instilled to the organizational members to enhance the achievement of organization's goals. Employee training is expected to assist in mitigation of frustration or anxiety that the work demands places on the employee in the form of unfamiliar tasks and lack of skills in effective handling (Chen et al., 2004).

According to Levy (2005), training is expected to be incorporated to management mindset and with the evolution and development of organizations, training becomes increasingly important. It is crucial for employees to adapt to the dynamic changes in the environment and to be capable of maintaining and keeping their capabilities up-to-date.

Employees lacking the competence to handle tasks are more likely to quit their employment (Chen et al., 2004) or if they stay, they are wont to display sub-optimal performance (Kanelopoulos \& Akrivos, 2006). The significant gap between the required skills and the employees' skills, often lead to dissatisfaction on the job and turnover intentions among employees. Despite the lack of direct relationship between training and job satisfaction in 
literature, it has been proposed by several studies that training may be utilized to enhance job satisfaction among employees (e.g., Rowden, 2002; Rowden \& Conine, 2005).

\subsubsection{Training Objectives}

Training objectives and priorities have to be established using a gap analysis that determines the employees' current level compared to the expected level. Once determined, the gap is filled with training objectives and priorities by providing training to improve knowledge and skills, and by enhancing employees' attitude. In this regard there are three types to training objectives and priorities and they are; knowledge (cognitive information with details), skills (developmental behavioral changes to the way jobs/tasks are conducted), and attitude (interest and awareness creation of what the training can provide).

There are four learning evaluation levels in Kirkpatrick \& Kirkpatrick's (2006) learning and training theory, which was introduced in 1959 simply as Kirkpatrick's learning and training evaluation theory. Theory has now become the most extensively utilized model and theory used to evaluate training and learning. The model's four levels primarily measure the following;

Level 1 - Student's reaction - what the student is thinking and feeling about the provided training.

Level 2 - Learning - the resulting knowledge/capability increase.

Level 3 - Behavior - the level improved and implemented behavior and capability of application.

Level 4 - Results - business/environmental effects stemming from the performance of the trainee.

\section{Training Methods}

The effectiveness of training whether using traditional-based or E-learning methods largely hinges on the model upon which the design of training is based on (i.e., presentation approach, hands-on method, team-building methods, classroom-based, lecture-based or face-to-face approach, e-learning, technology-based learning using CD-ROMs, DVDs, video conferencing and internet/intranet usage), allowing employees to learn from any location. Training method also involves the following components:

\subsubsection{Trainer's Characteristics}

Discussions on attributes and characteristics of effective trainers abound literature, with a list of provided by Bartlett (1982, cited in Goldstein \& Ford, 2002, pp.245-247). Bartlett (1982) described an effective trainer as one that offers a well-organized design of material sequence for optimum learning, conceptual learning and lectures and other course aspects, class discussions introducing ideas in each class, and interest stimulation for the subject among the trainees. 


\subsubsection{Reaction Level of Training Methods}

At the reaction level, based on Kirkpatrick's (1967) evaluation, the trainees thinking about the training program is emphasized. According to Buckley and Caple (2008), reactions display the opinions of trainees about four major areas; skills and knowledge content as displayed by the objectives of training, trainers and training methods, general learning conditions and environment, and the level to which attitudinal objectives are realized. In the same line of study, Goldstein and Ford (2002) revealed that this level's assessment calls for the provision of information of trainees concerning their satisfaction level with the trainer, the training management or the process of administration, the procedures of course testing, the use of training program and the course materials.

In relation to the above, the suitable time to measure the reactions of trainees to the training initiative has been a largely debated issue. In the take provided by Marchington and Wilkinson (1996), the typical practice is to gather data after the program culminates, whereas Buckley and Caple (2008) argued that data must be gathered during and after the training, and that a good approach of determining reactions is the use of learning journal. The journal helps trainees in recording their daily reactions or session reactions on a regular basis. The authors also suggested informal meetings and discussions as a good way to obtain information.

\subsubsection{Learning Level of Training Methods}

At the learning level, the concern is how to measure the knowledge, skills and attitude towards learning objectives. In this regard, it is important for the objectives to be expressed in a measurable and quantifiable way, and for them to encapsulate the required learning as argued by Bee and Bee (1994) and Goldstein and Ford (2002).

Attitudes or behaviors differ from one situation to the next (Bramley, 1996, p.89), and is thus challenging to assess. There are two primary reasons for this challenge, and the first being that trainees are aware of the right answer to provide and second, as opposed to assessing attitude, it is more feasible to assess behavioral changes within which the trainees operate (workplace). Bee and Bee (1994) and Bramley (1996) are of the consensus that changes in attitude at the workplace should be kept track of.

\subsubsection{Behavior Level of Training Methods}

Behavior is a term used to refer to the job performance measurement, (e.g., intermediate level) (Warr et al., 1970) and job behavior level (Hamblin, 1974), with the general aim of measuring the effect of training on job performance, and the effectiveness of learning that has been inculcated to the employees in the workplace context (Marchington \& Wilkinson, 2002). Nevertheless, in the case of levels measurement, it is significant that on-the-job measures are linked to well-established, clear and distinct objectives as suggested by Bee and Bee (1994), Bramley (1996), Goldstein and Ford (2002), Hamblin (1974) and Kirkpatrick (1967).

Moreover, job behavior level is mostly assessed by determining the way the job is conducted, which leads to the question of who conducts the assessment and how is it conducted? On the 
'who' question, there are different choices, in that employees themselves can conduct the evaluation (self-assessment), the supervisor or line manager, an independent expert or the peers and subordinates of the employee (Bee \& Bee, 1994; Reid \& Barrinton, 1997). As for the next part of the question, job behavior is assessed through three major methods namely, observation, self-completed questionnaires and interviews (Bee \& Bee, 1994).

\subsubsection{Results Level of Training Methods}

The organizational ultimate assessment (Warr et al., 1970) or the assessment level results (Hamblin, 1974) are the measurement of training effects on the performance of the organization (Bee \& Bee, 1994). This shows that this level of analysis is rife with tiring work, problems, and complexities as it is required for the analyst to take different issues (costs, turnover, grievances, absenteeism, and productivity levels) into consideration (Goldsteain \& Ford, 2002; Marchinton \& Wilkinson, 2002).

According to Bee and Bee (1994, p.258), this activity can be done through the following guidelines; identification of the major indictors/ measures of organizational performance for assessment (to be conducted in the training needs analysis stage), ensuring results are available in the correct form prior to the period of training, determining the training period, identifying other factors that may influence training and considering others to mitigate or measure the effects of factors, and finally, establishing suitable system for results monitoring.

\subsection{Effective Training Process}

Effectiveness of training involves processes happening prior to, during and following training that contributes to the likelihood of impact. Training evaluation is the level of the effectiveness of training and researchers and practitioners have assessed training impact based on outcomes (Kirkpatrick, 2005). Training is generally an approach to counter management issues concerning employees' job performance and efficiency on the job, while training effectiveness measures the level of effectiveness achieved through training by measuring job performance (Kraiger, 1993).

Training effectiveness aspects indicate the trainer's ability to inculcate knowledge, skills and ability through training initiatives (Lingham, 2006). With regards to whether or not the training initiative assisted in facilitating a positive culture in the organization, approximately $1 / 4^{\text {th }}$ of management and supervisors voiced the lack of necessity for trainees to provide their feedback on what they have learned or on the way they can apply learning. Others revealed that trainees often report on the both. Contrastingly, trainers take on the subject is that it is mandatory for trainees to inform managers and supervisors of the results and effects of training to allow them to facilitate a positive departmental culture. However, some trainers thought that training enhanced self-confidence of trainees, while others thought that it has not impact on it. Managers and supervisors meanwhile stated that training brings about improvement in the trainees' attitudes and behaviors.

On the basis of interview findings, majority of trainers lack involvement in post-training activities but this does not indicate that the other trainers play a key role in ensuring the transfer of job related skills. Majority of the participants in the managers' group also 
promoted the application of skills and knowledge learnt among trainees but whether or not such promotion is effective could be corroborated only through qualitative data. Therefore, managers and supervisors' methods are assumed not to be effective or rewarding.

\subsubsection{Types of Training}

Local companies do not place a lot of emphasis on the training needs analysis and provision of training for replacement objectives (Chew, 2005). According to Yong (2003), local firms possessing lower interest in enhancing employees' skills view training as a needs basis and limit it to those specific to the job. Local organizations management generally does not expected employees to be committed to lifelong learning, particularly when it comes to new technology and as such, employees do not consider enhancing their competence to be the driver to the successful career development.

\subsubsection{Training Environment}

The environment of training and learning contributes towards enhancing the effectiveness of training, with bad environment, emotionally affected and thereby they will lose some of the training effectiveness. Thus, training environment covers training facilities, layout of the site, sound lighting, hardware environment, classroom climate, student involvement in the soft environment. In training, both managers and trainers have to collaborate and cooperate to facilitate an optimum learning environment and atmosphere. Martin (2010) and Ford and Weissvein (1997) stated that training environment significantly impacts training effectiveness on HR practices among employees.

\subsubsection{Work Environment}

In the topic of training, majority of studies focused on training program design and the characteristics of trainees in the promotion of learning transfer, with attention also paid on the influence of the workplace environment. More specifically, work environment encapsulates various factors including, managerial support, peer encouragement, sufficient resources, opportunities to apply the skills learned, technological support and the outcomes of on-the-job training (Burke \& Hutchins, 2008; Colquitt et al., 2000; Kontoghiorghes, 2001; Lim \& Morris, 2006; Rouiller \& Goldstein, 1993; Tracey et al., 1995). According to findings, eradicating the barriers to work environment application is significant so much so that training opportunities have to be refused by employees if there is no follow-up support (Rossett, 1997). Training environment refers to the development of space where learning, assessment and interaction can happen in every way manageable. Researches on the topic (e.g., Becker et al., 1968; Synder, 1971; Dahlgren, 1978) stressed on the training environment factors, including assessment methods and course material that leads to effective performance of trainees.

\subsubsection{Training Design}

According to Farr's (1993) study, the training outcomes and trainees' reaction and learning depends on the content of training and thus, the unnecessary repetitive and misconceived content influence this factor (Lee, 1999). 


\section{Mll Macrothink}

Journal of Management Research

ISSN 1941-899X

2020, Vol. 12, No. 2

The training objective and content impart new knowledge, skills, behavior or attitude to individuals (Goldstein, 1993) and good training design contributes to enhancing employees' productivity. Molenda (2003) proposed a good approach to developing a training design by using instructional system development (ISD), which is a standardized training program, consisting of five criteria; analysis, design, development, implementation and evaluation. Each step involves informational outputs and controlled process decisions generation and incorporation to the next step.

\subsubsection{Relationship between Training Design and Training Effectiveness}

One of the top elements to successful training effectiveness is training goal and goal-matching between training design and training effectiveness is expected to enhance the performance of trainees (Yupawadee, Lesley \& Graham, 2008). Researchers in the training field identified factors related to one or more of these training and transfer outcomes and on the training design factors associated with the effectiveness of training. To begin with, Woodworth (1901) brought forward the identical elements principle as the core to training design. The principle posits that the knowledge and skills transfer will be its most optimum when there are similar stimulus and response elements existing in the setting of training and transference (Royer, 1979).

Notwithstanding the determination of the above contextual factors, their key role in training effectiveness has yet to be explicitly examined. In the context of training design, motivation must bring about the employee's willingness to participate in a training program, and second, to exert effort towards the program, and to transfer what has been learned to the actual job (Quinones, 1995). It is thus likely that trainees cannot reap the training program benefits without being motivated. Alipour (2009) described training as a fundamental element to the nation's economic growth and well-being and as such, it is very important, considering that training pervades at all industry level to a national level and the well-being of the whole country is enhanced by it through the productivity of companies. Skilled employees are valuable in the company and they can improve their positions within and thus, for training to be effectively management, it is important to identify the training that is suitable to be provided to employees. First, majority of supervisors may perceive that they are morally responsible for providing training to their employees whether or not such employee are satisfied with their jobs, find their jobs frustrating, challenging, boring, significant or meaningless - this is a serious concern for supervisors.

Second, managers want to be aware of the factors that derive employees training and affect performance. Majority of organization heads are convinced that employee training programs can result in enhanced productivity, mitigation of absenteeism, and motivate performance. Theories on employee training and its effectiveness have focused on the overall employees' perception of training satisfaction or dissatisfaction. Presently, the importance lies in the understanding of what satisfied or dissatisfied the employees in training provided by the organization and as such, it is important to determine the causes of training resources that could contribute to training effectiveness. 
In the same line of study, Mayfield (2011) recommended that training effectiveness predicts employee training, indicating that a trained employee may have a likelihood to display training effectiveness and job behavior (Pelham, 2009).

\subsubsection{Evaluating Training Effectiveness}

Evaluation has been acknowledged as a critical and required step in the process of training but it is not often carried out in an extensive or organized manner. This may be exemplified by an instance in the U.S., where evaluation concentrated on trainees' response to the training program as opposed to determining if learning occurred or performance on the job has enhanced (Goldstein \& Ford, 2002). Along a similar line of argument, despite the high UK employers percentage claiming that they gauge training effectiveness, their evaluation method was often informed feedback from line managers/trainees (Holden \& Livian, 1992). In sum, limited or disorganized evaluation has been conducted to determine training as it remains unclear what to evaluate or due to the expensive or risky evaluation techniques that may result in showing that the objectives of training fell short of meeting the objectives (Goldstein \& Ford, 2002).

In the evaluation objective, a five-point Likert scale was created to address the dimensions of job profile, collecting information concerning personal characteristics (age and gender) and workplace aspects (location, center type). Such independent variables enable evaluation of learning transfer among professionals and specific groups. The improvements relating directly with the acquired skills via training are referred to the work areas that the skills are applied and they are; selection, homogenization of criteria and medicines use, management of information, doctor-patient relationship, protocols introduction, new instruments inclusion, among others. Other aspects are related to supporting the training application via various agents (trainer, direct boss) was also assessed. This held true for factors affecting implementation that concerns information of the personal characteristics aspects (motivation, expectative) and the organizational characteristics aspects (climate, available resources), that directly affect the acquired learning transfer. All of the above factors were reviewed from literature (e.g., Noe, 1996; Holton, 2005; Burke \& Hutchins, 2008) and have been chosen as the top factors in studies that adapt better to the health sector.

Furthermore, training evaluation refers to an organized data and information collection process for the purpose of evaluating the effectiveness of training (Goldstein \& Ford, 2002). This generic definition is adopted in the present study, using the four levels of evaluation provided by Kirkpatrick (1998).

Identifying appropriate indicators for training effectiveness, specifically when evaluating effectiveness criteria is tough challenging. Evaluating training has transformed into a significant training program aspect in the past several years. Organizations are responsible for the learning of their employees for ensuring that they transfer knowledge acquired to the actual workplace. Added to this, training evaluation involves mutual success/failure analysis and determining of the intent to enhance skills and knowledge in a continuous manner in the hopes of realizing proficiency at work (Billets, 1989). Authors of this caliber used one of the top organizational training evaluation frameworks brought forward by Kirkpatrick, known as 
the four levels of training criteria consisting of reaction, learning, behavior and results (Praslova, 2010) as previously mentioned.

Although, most organizations are not aware of the contribution of training to performance, researchers are still slow to determine to validate and evaluate such contribution (Rae, 2004). Huang (2001) explained that this is due to the stresses that are often placed on training quantity rather than quality. In different training and development areas, management finds it difficult, specifically in the management level training or training of human relations, as no quantitative outcomes are generated (Rae, 2004).

According to Lunenburg and Ornstein (2012), training effectiveness refers to the change results that stem from achieving the objectives and are utilized in making decisions. Along a similar line of definition, Ling (2007) defined effectiveness as the level to which students obtain the ability of achieving the objectives of the program, which is determined from their grades and production that is aligned with the plans.

In the same caliber of study, Warr and Fay (2001) contended that comparing training effectiveness between young and older employees may be unfavorable due to the learning decline in some skill dimensions. They also added that social pressure towards training participation may also not be as strong for younger employees. Meanwhile, Werner and DeSimone (2009) referred to training evaluation as the descriptive and judgmental information collection to ensure that training decisions are made effectively in light of selection, adoption, value and changes in different instructional content.

\subsubsection{Kirpatrick’s Training Effectiveness Model}

Training is considered to be among the optimum methods used to improve individuals' productivity and relaying organizational goals to novice workers (Kartini, 2010) and is a learning process involving knowledge, skills and attitudes acquisition directed towards improving employees' performance.

Employees are expected to adapt to dynamic changes in the workplace and hence, this calls for providing them training in order for them to be efficient and effective in providing quality service to customers (Schumaker, 2004). Training primarily aims to enhance knowledge, skills, attitudes and ability of employees and to transform them into effective workers that work towards achieving the goals of the organization (Dessler, 2008). In the context of public sector, the government has to develop a culture of organizational learning to promote ongoing reproduction of the public service (Kumpikaite, 2008).

Moving on to Kirkpatrick's model, the first level is called reaction or feelings held by the participants about the training program. This is a significant first step to evaluating the outcomes of the program. This is followed by the second level, which is learning and this is concerned with the knowledge outcomes or ideas, information and approaches of the training program that the trainees understand and retain. The third level is behavior, which is the outcome in that the actual on-the-job application of the ideas and approaches learned. In the final level, which is, results, the concern is laid on the overall end results achieved taking 
different forms such as, sales quotas met, cozy reductions, increased employee retention or satisfaction and other outcomes (Asraf, 2012).

\subsubsection{Reaction}

The reaction of the trainee has a key role in developing interest, intention and motivation to transfer learning (Kartini, 2010). Trainees' reaction mainly reflects their feelings and subjective evaluation of the importance and quality of training. It answers the questions of the perceptions held by the participants, including; Did they like/enjoy training? Was the training objectives completely achieved? Were personal objectives achieved? Was it relevant and important to the job at hand? Was the content relevant to the job? Was the content easy to follow? Were there enough exercises, simulations and role plays to assist in following? Were new ideas learned? What is the overall rating? Such evaluation is frequently referred to as the 'smileysheet'. In relation to this, positive response is significant to create sufficient motivation towards learning although it does not ensure learning, whereas a negative reaction further reduces the learning possibility.

Also, the positive/negative reaction of the trainee is noted to identify training transference to work environment in an effective manner. The trainee's positive reaction enhances his learning (Bhatti \& Kaur, 2010) and with such reaction, higher learning and learning transfer to the actual task is expected. Contrastingly, a negative reaction shows low interest level in the training content and activities, low learning level and lower degree of transference. Viewed from the perspective of Wang and Wang (2006), participation reaction has to be measured in both long and short term.

\subsubsection{Learning}

Many training programs have generally focused on learning because successful trainees could translate into successful performance and motivation towards learning transfer (Kartini, 2010). Learning is the level to which the participant's attitudes change, their knowledge increases, or their skills broadened because of training. This second level of evaluation of participants can determine how new skills are acquired. Evaluation can relate to the approach utilized for knowledge, skills and attitudes transfer. Evaluating this level involves beyond assessing the satisfaction of the learner and moves towards the level of the advancement of the students' skills, knowledge or attitude (Haslinda \& Mahyuddin, 2009).

In this regard, Rossi et al. (2010) related that learning style covers knowledge before training and this can be described as an element of training abilities as it is dependent on the ability and experience of the trainees to handle certain tasks. Thus, learning style can be utilized to address and resolve managerial issues, following a straightforward guideline. Incorporating a learning style becomes important, following the stress on the integration of learning styles to enhance the learning environment.

In a similar study, informal and unplanned learning was found to play a key role among employees (particularly older ones) more than formal and normal learning did (Weiss, 2009). However, empirical analyses done to determine the differences in training characteristics and effectiveness in the life cycle have been few and far between. Also, it has yet to be 
determined whether employees try to adopt training design and methods suitable to their preferences (Armstrong-Strassen \& Templer, 2005).

\subsubsection{Behavior}

Behavior entails examining the job behavior changes following training and the evaluation of this level is an attempt to determine the answer to the question; Are the new acquired skills, knowledge or attitudes used in the learner's actual work environment?. Evaluation therefore determines if the tasks are conducted in a different manner prior to and following training. For positive reactions and learning effects and changed behavior on the job, it is pertinent that skills transfer takes place. The transfer quality largely depends on the participant's received support from the supervisor (Kirkpatrick, 1998).

\subsubsection{Result}

Evaluation at this level determines the results towards the end of the training programs. Evaluation of results measures the progress realized at the level of the organization. This was often perceived as the bottom line - a level that measures how successful the program is in a way that the managers and executives can comprehend and see (increased production, enhanced quality, decreased costs, reduced accidents frequency, increased sales and higher profits or return on investment). From the viewpoint of business and organization, this is the overall reason behind training but is often ignored because results determination in financial terms is challenging to gauge and to relate with the training program directly as explained by Haslinda and Mahyuddin (2009).

\subsection{Readiness for Training}

Researchers generally assume that satisfaction stem from training characteristics in that when satisfaction levels are compared throughout courses, it is assumed that the differences in training organization play a key role in the satisfaction differences. This assumption fails to consider the evidence that evaluative responses, whether they are effective (Suls, Green \& Hillis, 1998), or job satisfaction constructs (Judge \& Bono, 2001) are significantly affected the characteristics of the respondents. These findings may be extended to the construct of training satisfaction. Trainee motivation should affect satisfaction as evidenced by trait measures.

\subsubsection{Predicting Training Motivation: Individual and Contextual Factors}

\subsubsection{Self-Efficacy}

Under this topic, self-efficacy refers to the self belief in one's capabilities to control events or to achieve the established goals (Wood \& Bandura, 1989). Based on research findings, self-efficacious individuals strongly belief in their task-related capabilities and lay down challenging goals compared to their low self-efficacious counterparts (Bandura, 1986). The former type of individuals may also possess higher training motivation levels. Colquitt et al.'s (2000) related meta-analysis evidenced that self-efficacy is a determinant of learning motivation and this is supported by prior studies that examined self-efficacy-training motivation relationship such as, Quinones (1995) and other training results like Gist, Stevens 
and Bavetta (1991) and Philips and Gully (1997). As a consequence, self-efficacy is assumed to be positively related to training motivation.

\subsubsection{Organizational Support}

Organizational support and the context of training have been deemed to be significant predictors of learning transfer (Noe \& Schmitt, 1986). Based on the demonstration of prior literature, differential effects on training outcomes function as the support source from supervisors/peers, with support being conceptualized as a function of its source. As a consequence, support can stem from direct supervision or from peers and in this study, both supervisor support and peer support are considered to be connected to training motivation and skill and learning transfer.

\subsubsection{Return on Investment (ROI) Model}

The Phillips ROI Model posits that for HRD to be incorporated into the strategic framework of the company and the nation, it needs to facilitate change, develop skills for the future and maintain a capable human resource. According to Phillips (???), from the perspective of a bottom-line argument, HRD programs have to enhance profitability and productivity, and create new markets and new opportunities and avenues for business. He also mentioned a second strategic initiative within which constructive and effective collaboration is a must between employees and management and this is achievable via collaborative efforts in problem-solving, enhancing operational performance and the effectiveness of the company. Also, a third strategic initiative calls for the need for measuring HRD effectiveness, with HRD staff to be accountable for their actions. This is the only way to meet the challenges of measuring the effects of programs and presenting its contribution to the goals or objectives of the corporation.

With regards to learner success in online training, there are two primary skills identified and they are; adapting old skills and habits from the traditional classroom to be used in online classroom, and developing and using e-learning skills and habits for online classroom (refer to Watkins \& Corry, 2004). Ranging from developing vocabulary of technology terms to preparing for success in online chat rooms discussions, developing the learning skills for online training involves taking on several skills and habits from traditional classroom and applying them in novel ways in online realm using technologies. Added to this, it is evident that some technologies have transformed learner's interaction with trainers, peers and course content, which calls for new study skills development (refer to Figure 1). 
technologies. In addition, some technologies have dramatically changed $\mathrm{h}$ interact with trainers, peers, and course materials, thus requiring the devel some new study skills (see figure 1 ).

Figure 1. Relating Online Success with Traditional Student Success Skills (1 Watkins \& Corry, 2004).

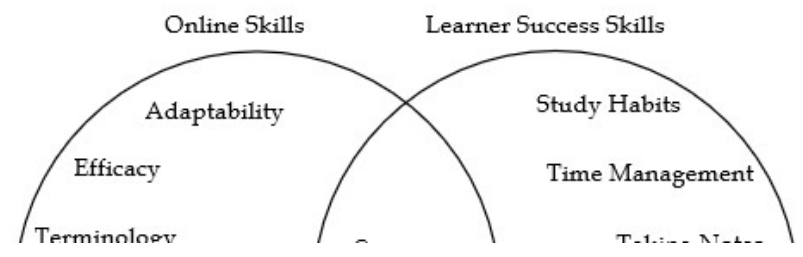

On the whole, the E-learning Readiness Self-Assessment is an instrument that is under development, and the present study shows that self-assessment capacity to measure the desired constructs of readiness for online training. On the basis of this necessity, data supported the validity of the self-assessment ongoing research to investigate the instrument's ability to predict future online courses performance. Additionally, the self-assessment instrument can be used by learners to identify their e-learning study skills to be developed in order to be successful in their learning experiences online.

The study skills recommendations can be used for the promotion of development of useful e-learning skills, study skills and technology skills and constructs to be revised in the future studies on self-assessment in order to keep abreast of the development of new technology and teaching strategies online.

\subsubsection{Trainee Readiness for Diversity Training}

Diversity training effectiveness of the trainee largely hinges on his/her attitudes and responses to diversity training and diversity-related knowledge and skills prior to attending a diversity training program. Based on prior training and diversity studies, this study highlights motivational, behavioral and cognitive readiness for diversity training. More specifically, motivational readiness covers pre-training motivation to learn and self-efficacy, while behavioral readiness covers pre-training intention to using the diversity content and pre-training perceived use. Cognitive readiness covers pre-training knowledge, skills and abilities on diversity. This section presents the why and how motivational readiness for diversity training may significantly impact the results of training (i.e., reactions/behaviors, training transfer and learning).

\subsubsection{Motivational Readiness for Diversity Training}

The learning motivation before training or pre-training learning motivation refers to the desire of the trainee to learn the training program content prior to participating in training (Facteau, Dobbins, Russell, Ladd \& Kudisch, 1995). Because the trainee's pre-training learning motivation is a determinant of the focus and the effort level in the program, it forms a focal factor that could contribute to the enhancement of training effectiveness, particularly in light of outcomes and transfer as evidenced by Warr and Bunce (1995) and Wiethoff 
(2004). Research on training revealed that pre-training motivation has a positive influence on training learning and transfer (Colquitt, Le Pine \& Noe, 2000). Low motivated learners may not activity participate in the training program, as a result of which, they may not achieve enhanced skills and knowledge concerning diversity (Mathieu, Tannenbaum \& Salas, 1992). As a result, low motivated trainees learn less and transfer less of the knowledge and skills obtained from the training diversity on the job (Facteau et al., 1995).

\subsubsection{Behavioral Readiness for Diversity Training}

The intention to use the content of the diversity training program before training reflects the intention of the trainee to use knowledge, skills and abilities (KSAs) that are learned from the program. The theory of planned behavior (TPB) proposed by Ajzen (1991) posits that the intention of the individual to perform a certain behavior is a predictor of his actual behavior. The intention assumptions indicate that a motivated individual is one that is inclined to put effort towards behavioral performance (p.181). Moreover, Ajzen's (1991) literature review indicated several evidence of the relationship between intention of different behavioral types (drinking, leisure, job search and class attendance). The TPB focuses on the intention to use specific knowledge and skills learned from the training program. The level of intention to use the training content thus predicts if the trainee will perform certain behaviors on the job. Stated clearly, the trainee's intention to use training contexts is a significant predictor of actual behavior and training transfer. In case the individual intends to use the training content in the pre-training level, then such motivation may increase learning and effect his/her actual behavior after obtaining training.

\subsubsection{Cognitive Readiness for Diversity Training}

This is the last dimension of trainee readiness for diversity training and in relation to this, training literature revealed that the knowledge, skills and attitudes (KSAs) of trainees prior to training may improve their learning but trainees with low KSAs may not be capable of learning the same way as those with high KSAs (Noe, 2010). Research dedicated to diversity training pinpointed the importance of trainees' KSAs; for instance, Kulik et al. (2007) revealed that employees with high EEO knowledge and cultural competence, which are behavioral/skill-based elements of diversity training, have a higher likelihood to voluntarily participate in a diversity training program. However, because trainees with low diversity-related KSAs are not aware of the deficits of their skills, they lack the motivation to learn the diversity training content and are unwilling to apply it in the workplace. Trainees with high diversity-related KSAs are more inclined towards enhancing such KSAs and have a higher likelihood of learning new KSAs and transferring them to the workplace.

\subsubsection{Contextual Characteristics and Trainee Readiness for Diversity Training}

The need of trainees for diversity training and subsequently form their readiness for diversity training may stem from diversity climate and relational demography. In particular, diversity climate is a critical factor used to enhance the performance of the organization through the fair treatment of employees notwithstanding their demographic backgrounds (Ely \& Thomas, 2001). This is because employees who feel that their organizational climate is supportive may 
enhance their cognitive and affective states (e.g., job motivation) (Chung, Liao, Subramony, Jackson, Colakoglu \& Jiang, 2011; Kopelman, Brief \& Guzzo, 1990). Meanwhile, relational demography is the level of similarity of individuals or group members attributes (Perry, Kulik \& Zhou, 1999), including not only the collective relationships between individual and peers, but also dyadic relationships between a boss and a subordinate. Various effects of relational demography have been addressed in literature using similarity-attraction paradigm. In other words, if the individual has similar attributes (physical, social and status) with other members of the group, he/she will have a higher likelihood to be attracted to join the group (Byrne, 1971).

\subsubsection{Learner Readiness}

Learner's readiness is the level to which an individual is prepared to participate in training (Holton et al., 2007, p.183). Empirical studies on training transfer relationship with other LTSI variables (e.g., learner readiness, transfer design and performance coaching) are still lacking. A prior study by Facteau et al. (1995) showed the significant role of learner's readiness in maintaining training reputation. Meanwhile, Payne et al. (2008) conducted a measurement of learner readiness in light of relevant knowledge and skills retention, and disposition or motivation towards the retrieval and application of knowledge. Their findings showed that learning transfer is at a higher level in cases where trainees are confident in retaining knowledge and motivated in applying it. This revealed that trainees that held knowledge concerning training program were more motivated to apply it and higher likelihood to transfer it in the workplace.

In addition, learner readiness concept was proposed by Bates et al. (2007) in light of; a program affecting performance, understanding of the job related developments, expectations from the provided training and expected results at the onset of training. In another related study, Kirwan and Birchall (2006) revealed that the trainee's motivation to transfer and his performance self-efficacy were significantly related with similar factors including learner readiness, transfer design, perceived content validity and use opportunity. Several other premises also advocated the collectively work of the factors. The authors found that leaner readiness had a significant effect on motivation to transfer. Some other items were also used to view learner readiness (Awais \& Sharan, 2010) and it is pertinent for the researcher to conduct an empirical examination of the learner readiness role in training transfer process with the inclusion of basic skills to perform various activities during training and basic knowledge about various tasks that the trainee requires for training performance (Awais \& Sharan, 2010).

\subsubsection{Training Retention}

Following training completion, the trainee may not effectively transfer training without the capacity to retain what has been learned in training. According to Velada et al. (2007), training retention is akin to the cognitive ability and it refers to the level to which the trainee manages to retain the content following the training process. Moreover, despite the fact that around $40 \%$ of content is immediately transferred after training, the amount transferred may decrease by $25 \%$ after six months, and $15 \%$ after a year (Wexley \& Latham, 2007). With the 


\section{Macrothink}

Journal of Management Research

ISSN 1941-899X 2020, Vol. 12, No. 2

passing of time, the trainees may be less inclined or capable of keeping or using information learned from training (Velada et al., 2007).

Ideally, contact and consultations between the company and trainers begin prior the training event and it goes on throughout and even after training (Bee \& Bee, 1994; Bramley, 1996; Harrison, 1992; Reid \& Barrington, 1997). But trainers often stop interfering after the completion of training and providing the performance report of the trainees and as such, determining what the trainees have learned and whether or not they will apply their learning on the job remains the trainees' and the managers' responsibility.

It is generally expected that the manager is the first to consult the training report for information on whether or not the training needs are met, action suggestions, and guidelines to change the status quo. Secondly, the manager would have a one-to-one discussion with the trainees to discuss their learning or otherwise, their application of learning to the job and their expectations of support from coworkers. When trainees receive support and feedback they will likely apply learning to their work behavior although the findings of the study are contrary to such statement.

\section{Hypotheses}

This study proposes the following hypotheses for testing;

H1: There is a positive and significant influence of training methods on effective training process in Ajman Police.

$\mathrm{H} 2$ : There is a moderating effect of readiness for training on the relationship between training methods and effective training process in Ajman Police.

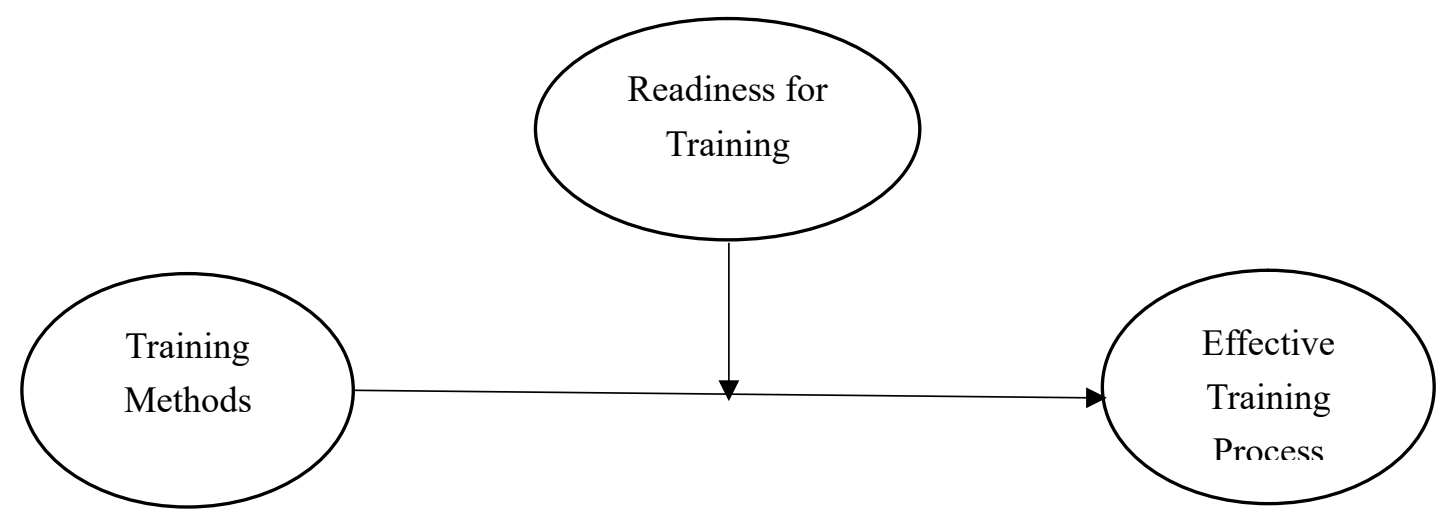

Figure 1. Research Framework 


\section{Methodology}

In order to examine the relationships among the study variables, the study adopts the quantitative methodology approach, using the questionnaire survey as the main instrument for collecting primary data from the respondents. The unit of analysis of this study is section of Ajman Police, in departments or police stations, where a total of 255 questionnaire copies were distributed. From the total questionnaire copies distributed, 172 were retrieved, indicating $67 \%$ rate of response. The study used the random sampling method to obtain the sample from the respondents and variables measurements were adopted from related prior literature.

More specifically, the main instrument of each variable was adopted for Noe (2008), which was translated by a certified agency into Arabic. Data collected was analyzed by structural equation modeling (SEM), while SmartPLS was used to test the proposed hypotheses.

\section{Data Analysis}

PLS-SEM was used to establish the outer model's reliability and validity, using Smart PLS 2.0. An essential step prior to examining the models and hypotheses is to test validity and reliability. This study examined the proposed model hypothesizing the joint effect of training methods and readiness for training on effective training process (ETP)

\subsection{Measurement of Outer Model}

Under this section, the construct validity and reliability of the outer model is presented and discussed using content validity, convergent validity and discriminant validity.

\subsubsection{Content Validity}

In studies dedicated to multivariate analysis, content validity refers to the high loadings of the constructs' items on their respective construct more than other model constructs (Chin, 1998; Hair et al., 2010). Items loading highly on other constructs other their own respective ones are dropped. In this study, the results showed that content validity was established for the measurement model as presented in Table 1. The table shows that all the constructs significantly loaded to their corresponding constructs.

\subsubsection{Convergent Validity}

Convergent validity is described as the level to which a group of items converges to measure a certain construct (Hair et al., 2010) and is measured by using factor loadings, composite reliability and average variance extracted (AVE). Loadings should significantly load when measuring variables at 0.7 , and AVE values have to be 0.5 for each construct, while composite reliability values have to be at least 0.7 . Table 2 tabulates the results and the recommended criterion of are met (Bagozzi \& Yi, 1988) and thus establishing convergent validity of the model. 
Table 1. Cross Loadings of the Items

\begin{tabular}{|c|c|c|c|}
\hline Construct & ETP & Readiness for Training & Training Methods \\
\hline ETP1 & 0.758 & 0.445 & 0.590 \\
\hline ETP10 & 0.801 & 0.531 & 0.631 \\
\hline ETP11 & 0.772 & 0.572 & 0.640 \\
\hline ETP12 & 0.757 & 0.613 & 0.512 \\
\hline ETP13 & 0.570 & 0.448 & 0.342 \\
\hline ETP14 & 0.718 & 0.525 & 0.495 \\
\hline ETP15 & 0.751 & 0.602 & 0.511 \\
\hline ETP16 & 0.811 & 0.517 & 0.582 \\
\hline ETP17 & 0.778 & 0.513 & 0.625 \\
\hline ETP2 & 0.731 & 0.423 & 0.551 \\
\hline ETP3 & 0.702 & 0.422 & 0.545 \\
\hline ETP4 & 0.790 & 0.557 & 0.628 \\
\hline ETP5 & 0.630 & 0.443 & 0.397 \\
\hline ETP6 & 0.774 & 0.646 & 0.589 \\
\hline ETP7 & 0.787 & 0.624 & 0.625 \\
\hline ETP8 & 0.745 & 0.583 & 0.551 \\
\hline ETP9 & 0.800 & 0.513 & 0.565 \\
\hline RfT1 & 0.446 & 0.644 & 0.430 \\
\hline RfT2 & 0.532 & 0.673 & 0.425 \\
\hline RfT3 & 0.396 & 0.643 & 0.372 \\
\hline
\end{tabular}




\begin{tabular}{llll} 
RfT4 & 0.511 & 0.763 & 0.472 \\
RfT5 & 0.510 & 0.829 & 0.438 \\
RfT6 & 0.525 & 0.812 & 0.463 \\
RfT7 & 0.605 & 0.654 & 0.544 \\
TM1 & 0.521 & 0.536 & 0.555 \\
TM2 & 0.589 & 0.574 & 0.807 \\
TM3 & 0.605 & 0.624 & 0.820 \\
TM4 & 0.391 & 0.377 & 0.680 \\
TM5 & 0.490 & 0.465 & 0.755 \\
TM6 & 0.624 & 0.533 & 0.863 \\
TM7 & 0.542 & 0.393 & 0.752 \\
TM8 & 0.637 & 0.416 & 0.792 \\
TM9 & 0.629 & 0.396 & \\
\hline
\end{tabular}

Table 2. Convergent Validity Analysis

\begin{tabular}{|c|c|c|c|c|c|}
\hline Construct & & $\begin{array}{l}\text { Cronbach's } \\
\text { Alpha }\end{array}$ & rho_A & $\begin{array}{l}\text { Composite } \\
\text { Reliability }\end{array}$ & $\begin{array}{l}\text { Average } \\
\text { Variance } \\
\text { Extracted (AVE) }\end{array}$ \\
\hline ETP & & 0.950 & 0.953 & 0.955 & 0.560 \\
\hline $\begin{array}{l}\text { Readiness } \\
\text { Training }\end{array}$ & for & 0.843 & 0.847 & 0.882 & 0.519 \\
\hline $\begin{array}{l}\text { Training } \\
\text { Methods }\end{array}$ & & 0.907 & 0.914 & 0.925 & 0.580 \\
\hline
\end{tabular}




\subsubsection{Discriminant Validity}

SEM literature defines discriminant validity as the level of set of items differentiation of a variable form another in the model. The construct's items should differentiate between them more than the variance shared with other constructs. Henseler et al. (2015) indicated that HTMT value should not exceed 1 for discriminant validity to be present, whereas Gold, Malhotra and Segars (2001) recommended a value lower than 0.90. In addition, Kline (2010) stated that the value should be less than 0.85 . Table 3 values meet the criteria HTMT ratio values and are therefore deemed to be acceptable.

Table 3. Discriminant Validity Matrix

\begin{tabular}{llll}
\hline Construct & ETP & $\begin{array}{l}\text { Readiness for } \\
\text { Training }\end{array}$ & $\begin{array}{l}\text { Training } \\
\text { Methods }\end{array}$ \\
\hline ETP & 0.748 & & \\
Readiness for Training & 0.711 & 0.721 & 0.762 \\
Training Methods & 0.745 & 0.632 & \\
\hline
\end{tabular}

\subsection{Structural Model (Inner Model) and Hypotheses Testing}

After the testing and confirmation of the construct validity and reliability, the next step involves the examination of the proposed hypotheses using SmartPLS Algorithm and Bootstrapping method. Table 5 and Figures 2 and 3 tabulate and present the obtained results respectively. Figure 2 and Table 5 indicate that training method has a positive and significant influence on ETP at the level of significance $0.001 \quad(\beta=0.422, t=5.508, p=0.001)$, while readiness for training moderated the relationship between training methods and ETP at the level of significance of $0.05(\beta=0.067, t=2.132, p=0.05)$. The results showed support for both proposed hypotheses ( $\mathrm{H} 1$ and $\mathrm{H} 2)$.

\subsection{Goodness of Fit (GoF) of the Model}

PLS-SEM only measure for the model fitness is GoF (Tenenhaus \& Vinzi, 2005). The fit is measured by calculating the average R2 and the AVE geometric mean of the endogenous constructs. 
Table 4. Goodness of Fit

\begin{tabular}{lll}
\hline Construct & R square & AVE \\
\hline ETP & 0.65 & 0.56 \\
Readiness for Training & & 0.519 \\
Training Methods & & 0.580 \\
\hline Average & 0.65 & 0.553 \\
GoF & $\mathbf{0 . 6 0 0}$ & \\
\hline
\end{tabular}

Table 5. Hypotheses Testing Results

\begin{tabular}{|c|c|c|c|c|c|c|c|}
\hline Hypothesis & Hypothesis & & $\begin{array}{l}\text { Path } \\
\text { Coefficient }\end{array}$ & $\begin{array}{l}\text { Standard } \\
\text { Error }\end{array}$ & $\begin{array}{l}\text { T } \\
\text { Value }\end{array}$ & $\begin{array}{l}\mathbf{P} \\
\text { Value }\end{array}$ & Decision \\
\hline H1 & $\begin{array}{l}\text { Training } \\
\text { Methods } \\
\text { ETP }\end{array}$ & $->$ & 0.422 & 0.077 & 5.508 & 0.000 & Supported \\
\hline $\mathrm{H} 2$ & $\begin{array}{l}\text { Training } \\
\text { Methods } \\
\text { Readiness } \\
\text { Training-> } \\
\text { ETP }\end{array}$ & $\begin{array}{r}* \\
\text { for }\end{array}$ & 0.067 & 0.032 & 2.132 & 0.034 & Supported \\
\hline
\end{tabular}




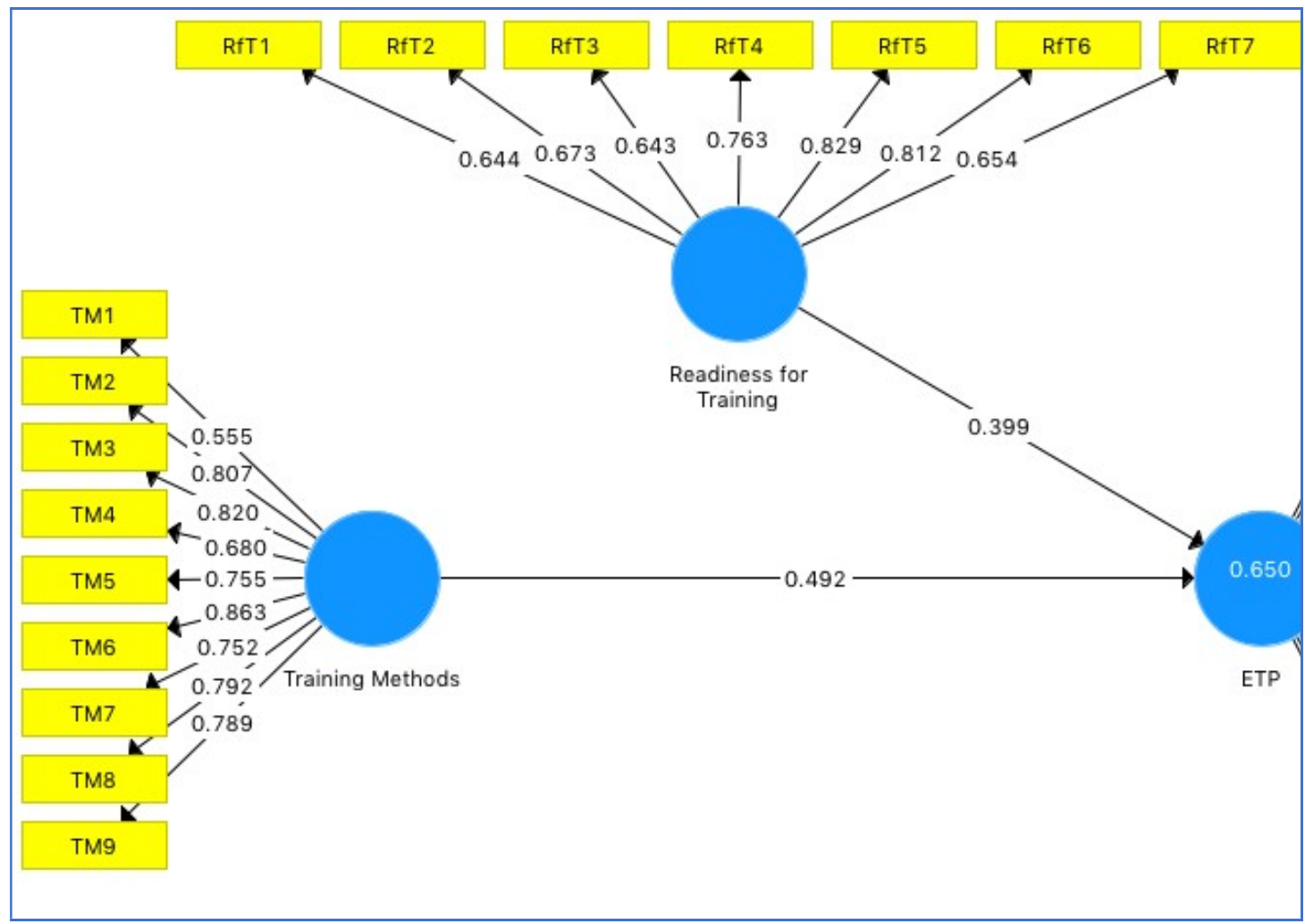

Figure 2. Path Coefficient Results

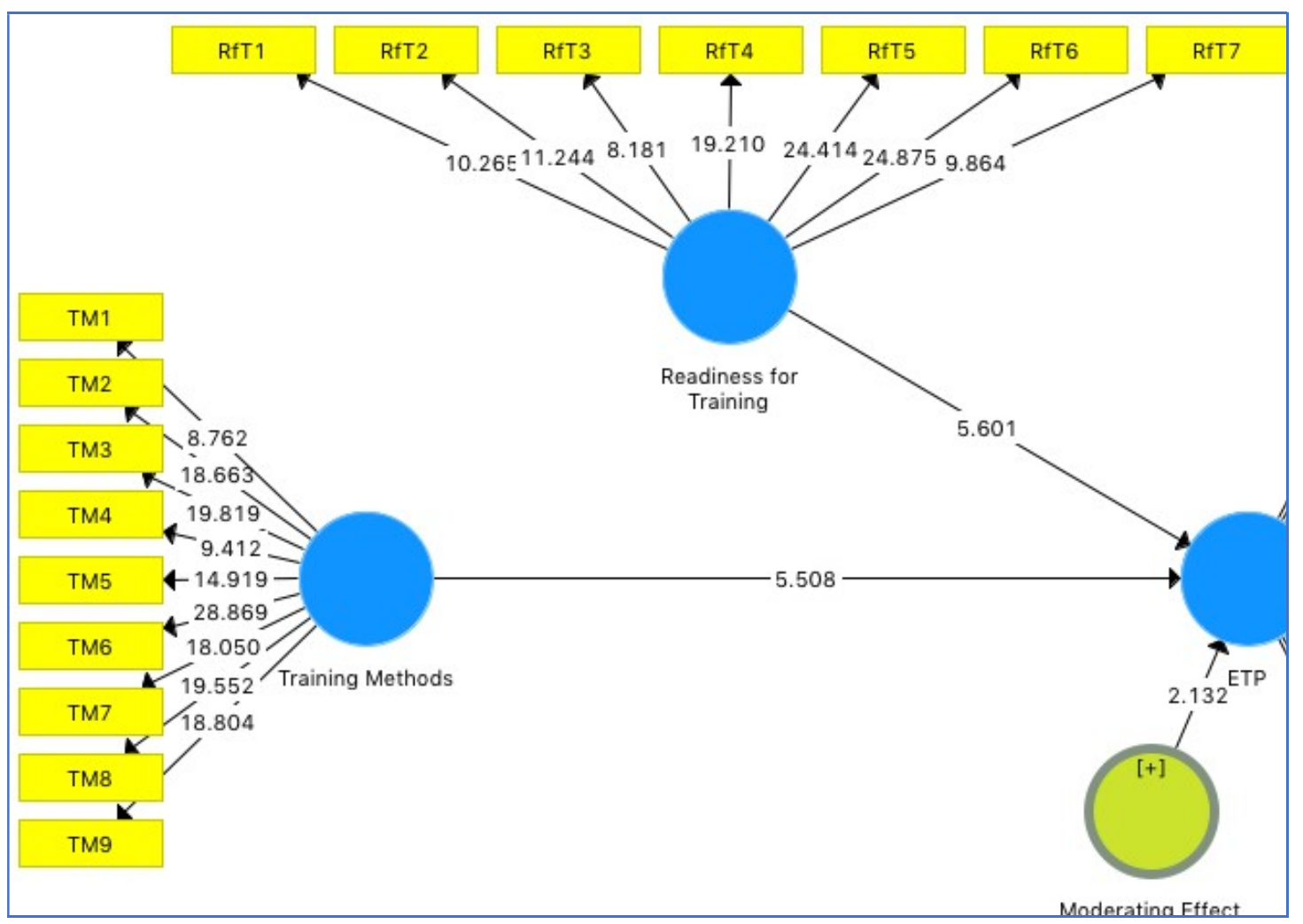

Figure 3. Hypotheses Testing Results 


\section{Discussions and Conclusion}

This study primarily aimed to examine the influence of training methods on ETP, with the moderating influence of readiness for training on the mentioned relationship. Because of the inconsistent and mixed results in literature concerning the relationship among training methods, readiness for training and ETP, this study conducted an empirical examination of the relationship. The study data was collected using questionnaire surveys distributed to Ajman police sections and the proposed model was tested with the help of PLS-SEM. Based on the statistical results, both proposed hypotheses were supported. In particular, there was a significant and positive relationship between training methods and ETP at the level of significance of $0.001 \quad(\beta=0.422, \mathrm{t}=5.508, \mathrm{p}=0.001)$, which supports other prior studies in literature (e.g., Dessler, 2008; Kirkpatrick, 2005; Kumpikaite, 2008; Schumaker, 2004). Moreover, there was a significant moderating effect of readiness for training on the relationship between training methods and ETP at the level of significance $0.05 \quad(\beta=0.067$, $\mathrm{t}=2.132, \mathrm{p}=0.05$ ), which supports prior studies (e.g., Goldstein \& Ford, 2002; Suls, Green \& Hillis, 1998; Judge \& Bono, 2001).

This study has several contributions to theory and practice. The theoretical contribution is the study's examination of the joint effect of training methods and readiness for training on ETP, while the practical contribution is its assistance to practitioners, managers and decision makers in enhancing ETP using training methods, through trainees' readiness for training.

\section{Recommendation and Future Suggestions}

Training process is one the most effective processes to develop human resources in organizations. Based on the results of this research, training methods are very important to have effective training process. In addition, readiness of trainees in the training process is also important where it showed to strengthen the effect of training methods of ETP. Therefore, it is recommended in organizations to have good selections of training methods for better ETP. Moreover, they have to prepare their employees to receive the training in positive impression. This can be achieved through clarifying employees' objectives and why they have to be involved in training process. In addition, organizations should increase the awareness among employees about the importance of training process for their success and career development.

\section{References}

Aamodt, M. (2012). Industrial/organizational psychology: An applied approach. Cengage Learning.

Abdul Hameed Aamer Waheed. (2011). -Employee Development and Its Effect on Employee Performance A Conceptual Frameworkll. International Journal of Business and Social Science, 2(13) [Special Issue - July 2011] 224.

Academy of Marketing Science, 16(1), 74-94. 
Adi, D.Y. (2000). Motivation as a Means of Effective Staff Productivity in the Public Sector: A Case Study of Nigerian Immigration Service, Borno State of Nigeria. Unpublished MPA Thesis. School University of Maiduguri Nigeria.

Alliger, M., Tannenbaum, I., Bennet, W., Traver, H., \& Shotland, A. (1997). A meta-analysis of the relations among Training criterias. Personal Psychology, 341-358. https://doi.org/10.1111/j.1744-6570.1997.tb00911.x

Alliger, M., Tannenbaum, I., Bennet, W., Traver, H., \& Shotland, A. (1997). A meta-analysis of the relations among Training criterias. Personal Psychology, 341-358. https://doi.org/10.1111/j.1744-6570.1997.tb00911.x

Anderson, R. J. \& Adams, W. A. (2015). Mastering Leadership: An Integrated Framework for Breakthrough Performance and Extraordinary Business Results. Wiley. https://doi.org/10.1002/9781119176510

Anka, L. M. A. (1988). March-April. Corporate Objectives and Self Development: The Specialist International. Journal of Institute of Management Specialist, 3, 5.

Auten, J. (1976). The paramilitary model of police and police professionalism. In A. S. Blumberg \& E. Niederhoffer (Eds.), The ambivalent force: Perspectives on the police. New York, NY: CBS.

Bagozzi, R., \& Yi, Y. (1988). On the evaluation of structural equation models. Journal of the Academy of Marketing Science. $\quad$ https://doi.org/10.1007/BF02723327

Beardwell, I. H. (2004.). Human Resources Management a contemporary Approach (4th ed.). (Harlow, Ed.) Prentice Hall.

Boundless Management. (2017). Employee Needs and Motivation. Accessed 3.9.2017. https:/www.boundless.com/management/textbooks/boundlessmanagement-textbook/organiz ational-behavior-5/employee-needs-andmotivation-46/maslow-s-hierarchy-of-needs-171-762 $1 /$

Brown, \& Gerhardt. (2002). Formative evaluation: an integrative practice model and case study. Personnel Psychology, 951-983. https://doi.org/10.1111/j.1744-6570.2002.tb00137.x

Brown, G. G. (n.d.). Formative evaluation: An integrative model and case study. Personnel Psychology, 55(4), 951-983. Brown, J. a. (n.d.). "Evaluation of Management Programs... An innovative approach". Personnel, 31. https://doi.org/10.1111/j.1744-6570.2002.tb00137.x

Chiaburu, D.S., \& Marinova, S.V. (2005). What predicts skill transfer? An exploratory study of goal orientation, training self-efficacy, and organizational supports. International Journal of Training and Development, 9(2), 110-23. https://doi.org/10.1111/j.1468-2419.2005.00225.x 


\section{Macrothink}

Journal of Management Research ISSN 1941-899X 2020, Vol. 12, No. 2

Chin, W.W. (1998). The partial least squares approach for structural equation modeling. in Marcoulides, G.A. (Ed.), Modern Methods for Business Research, Lawrence Erlbaum Associates, London, pp. 295-236.

Cohen, J. (1988). Statistical Power Analysis for the Behavioral Sciences, 2nd ed., Lawrence Erlbaum.

Colquitt, J. A., LePine, J. A., \& Noe, R. A. (2000). Toward an integrative theory of training motivation: A meta-analytic path analysis of 20 years of research. Journal of Applied Psychology, 85(5), 678-707. https://doi.org/10.1037/0021-9010.85.5.678

Cronbach, L. J. (1963). Educational psychology (2nd ed). New York: Harcourt Brace. https://doi.org/10.1037/14353-000

Dessler, G. (2005). A Framework for Human Resources Management. Prentice-Halled., Prentice Hall, Upper Saddle River, NJ.

Fitts, P. M. (1964). Perceptual-motor skill learning. In A. W. Melton (Ed.). Categories of human learning (pp. 243-285). New York: Academic Press. https://doi.org/10.1016/B978-1-4832-3145-7.50016-9

Generalized multiblock analysis. Journal of Chemometrics, 19(3), 145-153.

Giran, H., Amin, A., \& Halim, B. A. (2014). The impact of self-efficacy towards training motivation at Kolej Poly-Tech MARA Kuantan. Malaysia. Asian Social Science, 10(19), 69-76. https://doi.org/10.5539/ass.v10n19p69

Gist, M.E., Stevens, C.K., \& Bavetta, A.G. (1991). Effects of self-efficacy and post-training intervention on the acquisition and maintena.nce of complete interpersonal skills. Personnel Psychology, 44(4), 837-61. https://doi.org/10.1111/j.1744-6570.1991.tb00701.x

Gleeson, B. (2016). The Best Ways to Motivate Employees and Get Results. Accessed 3.9.2017.

https://www.forbes.com/sites/brentgleeson/2016/11/30/the-bestways-to-motivate-employeesand-get-results/2/\#6eb685273035

Goldstein, I. L., \& Ford, J. K. (2002). Training in organizations: Needs assessment, development, and evaluation (4th ed.). Belmont, CA: Wadsworth.

Griffiths, C. T., Klein, J. F., \& Verdun-Jones. S. N. (1980). Criminal justice in Canada: An introductory text. Toronto, ON: Butterworths.

Haberfeld, M. R. (2013). Critical issues in police training (3rd ed.). Boston, MA: Pearson.

Hair, J.F., Anderson, R.E., Tatham, R.L. and Black, W.C. (2010). Multivariate Data Analysis, $5^{\text {th }}$.

Hamblin, A. (1974). Evaluation and Control of Training. Maidenhead: McGraw-Hill. 


\section{Macrothink}

Journal of Management Research

ISSN 1941-899X

2020, Vol. 12, No. 2

Haslinda ABDULLAH. (2009). Major Challenges to the effective management of human resource training and development activities. The Journal of International Social Research, 2(8).

Henry Ongori. (2011). Jennifer Chishamiso Nzonzo

Herzberg, F. (1987). One More Time: How Do You Motivate Employees? Harvard Business Review, 65, 5.

Herzberg, F., B., Mausner, \& Snyderman, B. (1959). The Motivation to Work. New York, John Wiley \& Sons.

Higgins, J. (1994). The Management Challenge (2 ${ }^{\text {nd }}$ ed). New York.

Macmillan. Hillsdale, NJ.

International Atomic Energy Agency. (2003, july). Means of evaluating and improving the effectiveness of Training of nuclear power plant personnel. (I. John, Ed.) Human Resources Management.

Kaufman, R., \& Keller, J. M. (1994). Levels of evaluation: beyond Kirkpatrick. Human Resource Development Quarterly, 5(4), 371380. https://doi.org/10.1002/hrdq.3920050408

Kirkpatrick, D. (1976). Evaluating of training. New York: McGrawHill.

Klein, H. J., Noe, R. A., \& Wang, C. (2006). Motivation to learn and course outcomes: The impact of delivery mode, learning goal orientation, and perceived barriers and enablers. Personnel Psychology, 59, 665-702. https://doi.org/10.1111/j.1744-6570.2006.00050.x

Manzoor, Q. A. 2012. Impact of Employees Motivation on Organizational Effectiveness. European Journal of Business and Management, 3. https://doi.org/10.5296/bms.v3i1.904

Mathieu, J. E., Martineau, J. W., \& Tannenbaum, S. I. (1993). Individual and situational influences on the development of self-efficacy: Implications for training effectiveness. Pesonal Psychology, 46(1), 125-147. https://doi.org/10.1111/j.1744-6570.1993.tb00870.x

Mathieu, J.E., Tannenbaum, S.I., \& Salas, E. (1992). Influences of individual and situational characteristics on measures of training effectiveness. Academy of Management Journal, 35(4), 828-47. https://doi.org/10.2307/256317

McGehee, W., \& Thayer, P. W. (1961). Training in business and industry. New York: Wiley. Mondy, R. (2005). Human Resources Management (International Edition ed.). (9th, Ed.) Prentice Hall.

Montesino, M.U. (2002). Strategic alignment of training, transfer-enhancing behaviors, and training usage: a post-training study. Human Resource Development Quarterly, 13(1), 89-108. https://doi.org/10.1002/hrdq.1015

More, H. W., Wegner, F. W. \& Miller, L. S. (2003). Effective Police Supervision, Cincinnati, Anderson Publishing Co. 
Nahavandi, A., \& Malakzadeh, A. (1999). Organizational Behaviour: The Person Organizational Fit. New Jersey. Prentice Hall.

Noe, R. \&. (2002). Employee training \& development. Boston: McGraw-Hill Irwin.

Noe, R. A. (2008). Employee training and development (4th ed.). New York: McGrawHill Irwin.

Phillips, J. J. (1997). Handbook of training evaluation and measurement methods. Routledge.

Rainey, H.G. (1993). Work Motivation, In R.T. Golembiewski (Ed) Hamdbook of Organization Behaviour, pp. 19-39, New York, Marcel Dekker.

Rajeev, P. M. (2009, January 29). Revisiting Kirkpatrick model- an evaluation of an academeic training course. Current Science, 96(2).

Roberg, R., \& Bonn, S. (2004). Higher education and policing: Where are we now? Policing: An International Journal of Police Strategies and Management, 26(2), 313-328.

Rothberg, G. (2005). Fourth Quarter. The Role of Idea in the Managers Workplace: Theory and Practice. Pakistan Management Review, XLII(4), 48-73.

Salas, E. and Cannon-Bowers, J.A. (2001). The science of training: a decade of progress. Annual Review of Psychology, 52, 471-99. https://doi.org/10.1146/annurev.psych.52.1.471

Salas, E., Rozell, D., Mullen, B., \& Driskell, J.E. (1999). The effect of team building on performance: an integration. Small Group Research, 30(3), 309-29. https://doi.org/10.1177/104649649903000303

Salas, Eduardo, \& Janis A. Cannon-Bowers. (2001). The science of training: A decade of progress. Annual review of psychology, 52(1), 471-499. https://doi.org/10.1146/annurev.psych.52.1.471

Sleezer, C. M. (1993). Training needs assessment at work: A dynamic process. Human Resource Development Quarterly, 4, 247-264. https://doi.org/10.1002/hrdq.3920040305

Tenenhaus, M., \& Esposito Vinzi, V. (2005). PLS regression, PLS path modeling and generalized. https://doi.org/10.1016/j.csda.2004.03.005

Webster, J., \& Martocchio, J.J. (1993). Turning work into play: implications for microcomputer software training. Journal of Management, 19(1), 127-46. https://doi.org/10.1177/014920639301900109

Worthen, Blaine R., James R. Sanders, \& Jody L. (1997). Fitzpatrick. Program evaluation. Alternative approaches and practical guidelines, 2.

Yong, K. (2003). Human Resources Management in Malaysia Institute of Management. 230250.

Zikmund, G. W. (2003). Business Research Methods. Oklahoma: South-Western. 